\title{
Queuine mediated inhibition in phosphorylation of tyrosine phosphoproteins in cancer
}

Chandramani Pathak · Yogesh K. Jaiswal • Manjula Vinayak

Erratum to: Mol Biol Rep

DOI 10.1007/s11033-007-9095-1

This erratum has been initiated due to incorrect figure legends.
Legends for Figs. 1 and 2 appear as +S.E.M. in the original publication, and should be read as mean \pm S.E.M.

The online version of the original article can be found under doi: 10.1007/s11033-007-9095-1.

C. Pathak · Y. K. Jaiswal · M. Vinayak $(\bowtie)$

Biochemistry \& Molecular Biology Laboratory, Center of Advanced Study in Zoology, Banaras Hindu University,

Varanasi 221005, India

e-mail: manjulavinayak@rediffmail.com

C. Pathak · Y. K. Jaiswal

School of Studies in Biochemistry, Jiwaji University, Gwalior

474011, India 